\title{
Healthy aging as a solution to the 'ticking time bomb': dealing with aging population in urban china
}

\begin{abstract}
Health is considered an important determinant of economic growth and competitiveness. The health of the elderly population determines its need for resources and care. Investing in healthy aging contributes to economic and social well-being. This study reviews literature on the social and economic aspects of healthy aging. It summarizes alternative approaches in literature to ease pressures of a rapidly growing aging population. Literature refers to China's aging population as a 'ticking time bomb' which is paradoxically both a challenge and an opportunity for the country. This study's main focus is on strategies for healthy aging, policy practices, organizations and resources for promoting healthy aging in China. It uses up-to-date theories and methods applied to household surveys and population statistics to quantify the problem generate an idea of the resource requirements and possible benefits of specific policies and measures aimed at healthy aging. It draws conclusions with respect to the conditions of healthy aging in China and what the state policy for this is.
\end{abstract}

Keywords: healthy aging, aging in china, active aging, challenges and opportunities, economics of healthy aging, JEL classification codes: H75, I15, I18, I38, P36
Volume 2 Issue 2 - 2018

\author{
Almas Heshmati \\ Department of Economics, Sogang University, South Korea
}

Correspondence: Almas Heshmati, Department of Economics, Sogang University, South Korea, Tel +82-2-705-877।,

Email heshmati@sogang.ac.kr

Received: Januvary 08, 2018 | Published: April 17, 2018

\section{Introduction}

According to the World Health Organization (WHO), health refers to physical, mental and social well-being. ealthy aging is defined as developing and maintaining optimal health and functions in older adults. These are most likely to be achieved when communities are safe, health and well-being is actively promoted, the elderly use health services and there are various community programs to prevent or minimize the prevalence of various diseases. A policy for active aging is a public policy that aims to extend healthy life expectancies and the quality of life of all people as they age. The need for healthy aging is a major challenge for a large country like China which has the largest number of elderly people in the world. Aging will have an enormous impact on Chinese society. Literature refers to China's aging population as a 'ticking time bomb'. Some look at aging in China both as a challenge and also as an opportunity to influence aging in a desired direction. Health is also considered an important determinant of economic growth, social well-being and the competitiveness of a nation. The health of the elderly population determines its need for resources and care. This is particularly the case in societies with inclusive welfare service provisions. Thus, investing in healthy aging contributes positively to labor supply, decreases the likelihood of costly early retirement and lowers the cost of care. It is crucial for governments, in particular the Chinese government, to plan their aging related policies and allocating adequate health and welfare resources for the future.

There are some forces which impact healthy aging in China both positively and negatively. The positive forces include growth in the economy, higher educational advancements, technological developments, increasing detection and treatment of diseases and the availability of health insurance and health services. Further, the age gap or inequalities in longevity have also been reduced in the country. The negative forces center on disturbing trends in personal health behaviors such as an increase in smoking, obesity and pollution. Other changes are related to an increase in fertility rates and rural-to-urban labor migration separating elderly parents from their children who are traditionally expected to take care of the old. This study reviews literature on the social and economic aspects of healthy aging. It summarizes alternative approaches presented in literature to ease the pressures of a rapidly growing aging population. Its main focus is on strategies for healthy aging, policy practices and measures and organizations and resources employed for promoting healthy aging. It uses up-to-date theories and methods as applied to household surveys and population statistics to quantify the problem, estimating the resource requirements and estimating possible social and economic benefits of healthy aging policies and measures. It draws conclusions with respect to policies and the conditions of healthy aging in urban China. The rest of the study is organized as follows: Section 2 presents a literature review with specific focus on aging, health inequalities in a 'fair society' and measurements of healthy aging. Section 3 gives aging conditions in China. The next section discusses the economics and policies of healthy aging with emphasis on urban conditions. Various public investment programs for building infrastructure and other aspects such as diet and other preventive factors supporting healthy aging are discussed in Section 5. The next section discusses the experience gained which can be used for designing optimal healthy aging for China; it also gives relevant policy recommendations. The final section summarizes the important findings of the study.

\section{Aging and the evolution and measurement of healthy aging}

This section discusses the evolution of healthy aging and research on aging and aging-related topics. Here evolution refers to the many processes that drive physical, healthiness, social, environmental and economic transition of the elderly population conditions and its development. It also reviews health inequalities, a fair society and how healthy aging is measured. 


\section{The evolution of healthy aging}

As a result of progress in food supplies, technology and education, average life expectancy is increasing. Rasmussen et al. ${ }^{1}$ illustrate radical changes in this regard for less and more developed nations. The authors see the general increase in mean age of the population regardless of location and level of human development as a phenomenon that will bring social, political, economic and biomedical challenges for current and future generations worldwide. The International Alliance of Research Universities (IARU) holds a series of congresses on 'Aging, Longevity and Health' in Copenhagen to attract researchers with interest in aging and age-related topics. The Alliance observed major shifts in the demographics of urban populations in more developed nations in 2005 as compared to 1975. Rasmussen et al. ${ }^{1}$ highlight the outcomes of recent research on aging-related topics presented at the Congress. Their report gives details about the evolution of population age structures in urban and rural regions by levels of development over the last 50 years and projections for future changes in population age demographics. They predict that by 2050, 33 per cent of the developed countries and 22 per cent of the developing countries' populations will be over 60 years or there will be a doubling of the elderly population worldwide. The researchers used a multifaceted interdisciplinary approach to address the challenges that such an increase will pose. Their aim was to develop therapeutic interventions tested in elderly populations to investigate enhancements in the quality of human life, developing cost effective and efficient methods and reaching a consensus on how to allocate limited resources to meet the competing needs and priorities of different age groups.

\section{Health inequalities and healthy aging}

Inequalities can have many dimensions though income inequality is the most commonly studied one. Among the other dimensions studied are inequalities in assets, health, life expectancy, education, well-being, opportunities, gender gap and safety. The focus of this study is on the effects of health inequalities on healthy aging in the context of a fair society. Over the years Britain has commissioned a number of inquiries into health, including the Black Report in 1980, the Ashton Report in 1998 and the Marmot Review released in 2010. The Marmot Review is a strategic review of health inequalities in
England post-2010. It is an independent report which was undertaken with the aim of consolidating evidence on health inequalities and also for developing effective evidence-based strategies for reducing health inequalities in the country. The Review's four key tasks were:

a. Identifying evidence to inform policy and actions to reduce health inequalities.

b. Demonstrating how the evidence can be translated into practice.

c. Advising on objectives and measures for reducing mortality and increasing life expectancies.

d. Contributing to the development of a strategy that reduces health inequalities.

Marmot and Bell ${ }^{2}$ and Marmot et $\mathrm{al}^{3}{ }^{3}$ provide an overview of the findings of the Marmot Review by putting fairness at the heart of policymaking. The Marmot Review's ${ }^{4}$ key findings are presented in Subramanyan et al. ${ }^{5}$ under nine points aimed at reducing health inequalities. Chandra and $\operatorname{Vog} 1^{6}$ discuss the Review and its prescriptions from the perspective of economists. In their comments they focus on leaping over shorter distances between accumulated knowledge of causal systems and economically implementable policies.

\section{Measuring healthy aging}

Several techniques have been developed to measure healthy aging including both single and multidimensional measures with differing focus on biological aging, predictions of longevity and genetic healthy aging. Biological aging is a complex process. Lara et al. ${ }^{7}$ did not find a single, simple and reliable measure to find out how an individual aged in a healthy manner. The authors used the healthy aging phenotype (HAP) in large literature on lifestyle-based intervention studies to identify the key features of healthy aging and for identifying or developing tools for measuring these features. The selected domains included physiological and metabolic health, physical capabilities, cognitive functions, social well-being and psychological and subjective well-being. Due to limited spaces, the readers are referred to Lara et al. who provide a comprehensive review of measuring domains, sub-domains and healthy aging phenotypes listed in (Table 1).

Table I Tools for measuring selected domains and sub-domains of healthy aging

\begin{tabular}{|c|c|c|}
\hline Domain & Sub-domain & Measures of healthy aging phenotype \\
\hline \multirow{4}{*}{$\begin{array}{l}\text { I. } \\
\text { Physiological } \\
\text { and metabolic } \\
\text { health }\end{array}$} & I.I Cardiovascular function & Blood pressure; blood lipids \\
\hline & I.2 Lung function & Forced expiratory volume; blood glucose \\
\hline & I.3 Glucose metabolism & Glycated haemoglobin; waist circumference \\
\hline & I.4 Body composition & Waist to hip ratio; body mass index (BMI) \\
\hline \multirow{5}{*}{$\begin{array}{l}\text { 2. Physical } \\
\text { capabilities }\end{array}$} & 2.I Strength & Handgrip strength \\
\hline & 2.2 Locomotion & Gait speed \\
\hline & 2.3 Endurance & Walk endurance test \\
\hline & 2.4 Dexterity & Pegboard dexterity test \\
\hline & 2.5 Balance & Standing balance test \\
\hline \multirow{3}{*}{$\begin{array}{l}\text { 3. Cognitive } \\
\text { functions }\end{array}$} & 3.I Processing speed & Speed recreation time; symbol digit modalities test \\
\hline & 3.2 Episodic memory & Story recall; world list recall; paired associate learning \\
\hline & 3.3 Executive function & Stroop; trail making tests $A \& B$ \\
\hline
\end{tabular}


Table continued.

\begin{tabular}{|c|c|c|}
\hline Domain & Sub-domain & Measures of healthy aging phenotype \\
\hline \multirow{5}{*}{$\begin{array}{l}4 . \\
\text { Psychological } \\
\text { well-being }\end{array}$} & $\begin{array}{l}\text { 4.I Positive and negative } \\
\text { affects }\end{array}$ & Positive and negative affect schedule \\
\hline & 4.2 Life satisfaction & Satisfaction with life scale \\
\hline & 4.3 Quality of life & $\begin{array}{l}\text { Control, autonomy, pleasure and self-realization, quality of life scale; } \\
\text { WHO quality of life-BREF }\end{array}$ \\
\hline & 4.4 Mental health & $\begin{array}{l}\text { Center for epidemiological studies depression scale; Warwick- } \\
\text { Edinburgh mental well-being scale }\end{array}$ \\
\hline & 4.5 Resilience & Psychological resilience scale \\
\hline \multirow{4}{*}{$\begin{array}{l}\text { 5. Social well- } \\
\text { being }\end{array}$} & 5.I Social network & $\begin{array}{l}\text { Lubben social network scale; NIH toolbox: friendship; PROMIS: } \\
\text { companionship }\end{array}$ \\
\hline & 5.2 Social functioning & $\begin{array}{l}\text { Social isolation; PROMIS: satisfaction with social roles and activities; } \\
\text { revised UCLA loneliness scale }\end{array}$ \\
\hline & $\begin{array}{l}\text { 5.3 Perceived emotional/ } \\
\text { social support }\end{array}$ & $\begin{array}{l}\text { Social support behaviors scale; NIH toolbox: emotional support; } \\
\text { instrumental support; loneliness; perceived rejection scale }\end{array}$ \\
\hline & 5.4 Sense of purpose & NIH toolbox: psychological well-being; meaning and purpose \\
\hline
\end{tabular}

\section{Source adapted from Lara et al. ${ }^{7}$}

These were expected to provide a holistic characterization of the healthy aging phenotype. A second approach for measuring or predicting healthy aging is discussed by Vanhooren et al. ${ }^{8}$ who used $\mathrm{N}$-glycan profiles as measurement tools. Protein glycosylation is the most common form of the co-translational modification of proteins. It increases the diversity of the functions of proteins encoded in the genome. Therefore, an examination of alterations in the serumglycan fingerprint by using the suggested platform could be a suitable tool for monitoring the healthiness of aging and for assessing the effectiveness of aging interventions. It could also be useful in detecting and following up on health conditions and monitoring treatment effects. A third approach for measuring healthy human aging comes from the integrated European project Genetics of Healthy Aging (GEHA). The aim of the project was identifying genes involved in healthy aging and longevity. According to Shytthe et al. ${ }^{9}$ as the first step the project recruited pairs of siblings and a control group for each sibling pair from 11 European countries. It used 2,249 trios for genetic analyses. A follow-up of mortality improved the possibility of identifying families with the most extreme longevity phenotypes. The authors view the GEHA project as representing a unique source in a search for genes related to healthy aging and longevity.

\section{Aging conditions in china}

As stated earlier, health refers to physical, mental and social wellbeing. Healthy aging is developing and maintaining optimal health and functions among the elderly. This can be achieved when communities actively promote health and well-being. Thus, the aim of an active public aging policy is extending healthy life expectancies and the quality of life for citizens as they age. Maintaining older people's autonomy and independence is a key goal of the policy framework for active aging in Europe. Europe has a well-developed welfare system with large investments in elderly care and the quality of life. It is predicted that by 2025 about one-third of Europe's population will be aged 60 years and above. In addition, there will be a rapid increase in the number of people above 80 years with greater health service needs. This will have an enormous impact on societies as health is considered an important determinant of economic growth. Investing in healthy aging contributes to labor supply and in decreasing absenteeism and the likelihood of costly early retirement. Agren et al. ${ }^{10}$ study brings together information from literature on healthy aging and health determinants. It gives examples of good policies and strategies. Developing countries experience demographic changes in the form of lowered fertility rates and an increase in longevity leading to altered population age structures. China has more elderly people than any other country. According to China's 2010 Census, it had 119 million people aged 65 years and older, that is, 8.9 per cent of its population was aging fast. By 2050, China's aging population will match or exceed the populations of many of today's developed countries. Aging in China has three distinctive features: (i) By tradition Chinese people rely on their families for old-age support, (ii) Its population has seen a large decrease in the proportion of children as a result of the one-child policy, and (iii) China is undergoing rapid urbanization characterized by massive migration of younger workers from rural to urban areas. ${ }^{11}$

China's aging population is increasing and is likely to reach its peak by the middle of the $21^{\text {st }}$ century. Dong ${ }^{12}$ find the product and service scales and their qualities lagging far behind the needs of the elderly. They identified ways of addressing the aging population's needs and suggest improving education on geriatric and gerontology and supporting elderly institutions and elderly care for meeting increased needs and consumption demands. They used the methods used by other countries as a reference and adapted the methods to local conditions in China. Among their suggestions is making changes in traditional elderly care and concepts of death by introducing hospice care which is designed to give supportive care to people in the final phases of terminal illnesses. The older population's health also determines its needs for care. Smith et al. ${ }^{13}$ reviewed the positive and negative forces of healthy aging in China. According to them a positive force of healthy aging was associated with economic development and improvements in technology and education over time and with increasing detection and treatment of diseases and reforms that led to the availability of health insurance and health services. The negative forces centered on disturbing trends in personal health behaviors such as an increase in smoking, obesity and pollution. Other negative changes related to a changed child policy, increase in fertility rates and rise in migration leaving elderly parents geographically separated from their caretaker children. The authors suggest public health 
campaigns and a policy that allows elderly people to migrate to their children to meet the challenges of aging. Mohanty provides comments on Smith et al. ${ }^{13}$ policy interventions for healthy aging in China. One policy instrument is raising the retirement age to improve financial security and sustained economic growth. The positive and negative forces of gender disparities, education, longevity, smoking, obesity and health insurance, mentioned in Smith et al. ${ }^{13}$ were observed.

The Journal of the Economics of Aging ${ }^{14}$ published a special issue focusing on the economic aspects of an aging population in the world's two population superpowers - China and India. Its aim was to fill a gap in literature related to possible economic consequences of the demographic trajectories of their aging populations. Wang et al. ${ }^{15}$ discuss how population aging is challenging healthcare in China. They quote the China Research Center of Aging according to which the elderly population reached 202 million in 2011. More than 100 million had non-communicable diseases, 37 million had diabetes and about 23 million were older than 80 years leading to pressures on healthcare services; this also led to widespread social concerns. The authors point to the unfairness and disparities in the health insurance system and insufficient resources available for elderly care leading to a sub-optimum chain of services. They recommend accelerating the development of community-based primary healthcare for the elderly, with the aim to improving their basic knowledge about health, investing in health education and promoting health behavior. China's population and its composition for 1950-2014 are given in (Table 2). The population more than doubled from 552 million to 1,364 billion during this period. The male and female share of the population was around 51.5 and 48.5 per cent respectively. The urban share of the population increased from 11.18 to 54.90 per cent, while its rural share declined from 88.82 to 45.10 percent.

Table 2 China's population and its composition by gender and residence (1950-2014) (in 10,000)

\begin{tabular}{llllll}
\hline & Total & Urban & & Rural & \\
\hline Year & Population & Population & $\%$ & Population & $\%$ \\
\hline 1950 & 55,196 & 6,169 & 11.18 & 49,027 & 88.82 \\
1955 & 61,465 & 8,285 & 13.48 & 53,180 & 86.52 \\
1960 & 66,207 & 13,073 & 19.75 & 53,134 & 80.25 \\
1965 & 72,538 & 13,045 & 17.98 & 59,493 & 82.02 \\
1970 & 82,992 & 14,424 & 17.38 & 68,568 & 82.62 \\
1975 & 92,420 & 16,030 & 17.34 & 76,390 & 82.66 \\
1980 & 98,705 & 19,140 & 19.39 & 79,565 & 80.61 \\
1985 & 105,851 & 25,094 & 23.71 & 80,757 & 76.29 \\
1990 & 114,333 & 30,195 & 26.41 & 84,138 & 73.59 \\
1995 & 121,121 & 35,174 & 29.04 & 85,947 & 70.96 \\
2000 & 126,743 & 45,906 & 36.22 & 80,837 & 63.78 \\
2001 & 127,627 & 48,064 & 37.66 & 79,563 & 62.34 \\
2002 & 128,453 & 50,212 & 39.09 & 78,241 & 60.91 \\
2003 & 129,227 & 52,376 & 40.53 & 76,851 & 59.47 \\
2004 & 129,988 & 54,283 & 41.76 & 75,705 & 58.24 \\
2005 & 130,756 & 56,212 & 42.99 & 74,544 & 57.01 \\
2006 & 131,448 & 58,288 & 44.34 & 73,160 & 55.66 \\
\hline & & & & &
\end{tabular}

Table continued.

\begin{tabular}{llllll}
\hline & Total & Urban & & Rural & \\
\hline 2007 & 132,129 & 60,633 & 45.89 & 71,496 & 54.11 \\
2008 & 132,802 & 62,403 & 46.99 & 70,399 & 53.01 \\
2009 & 133,450 & 64,512 & 48.34 & 68,938 & 51.66 \\
2010 & 134,091 & 66,978 & 49.95 & 67,113 & 50.05 \\
2011 & 134,735 & 69,079 & 51.27 & 65,656 & 48.73 \\
2012 & 135,404 & 71,182 & 52.57 & 64,222 & 47.43 \\
2013 & 136,072 & 73,111 & 53.73 & 62,961 & 46.27 \\
2014 & 136,430 & 74,920 & 54.9 & 61,870 & 45.1 \\
$2014 /$ & 2.472 & 12.145 & 4.911 & 1.262 & 0.508 \\
1950 & & & & & \\
\hline
\end{tabular}

Source China statistical yearbook (2014)

\section{The economics and policies of healthy aging}

Economics helps determine resource requirements for alternative policies to address healthy aging. It can also help in identifying different alternative care systems and their associated costs and benefits. Various methods are used to estimate the effects of programs and for selecting the most cost effective care methods. The focus of economics is increasingly on issues of urban migration and investments in infrastructure, housing, health, education and child and elderly care.

\section{The economics of healthy aging}

Literature on aging has developed rapidly. Studies in this stream focus on the challenges of an aging population for healthcare, ${ }^{11}$ the role of globalizing local knowledge systems for diets and healthy aging, ${ }^{16}$ healthy aging and home in Europe, ${ }^{17}$ the aging of the Chinese population and the cost of healthcare, ${ }^{18}$ the role of urban design and healthy aging, ${ }^{19}$ factors of successful aging, ${ }^{20}$ aging, longevity and the health nexus, ${ }^{1}$ healthy aging in China, ${ }^{13}$ health status of the elderly ${ }^{21}$ and measuring healthy aging. ${ }^{6}$

When it comes to population projections for 2050 , Hou \& $\mathrm{Li}^{18}$ suggest that there will be about 115 million elderly citizens over 80 years of age in China. Coping with the care demands of the elderly will require serious planning. The authors provide quantitative measures of the elderly's dependency ratio and the cost of medical insurance. The medical insurance premium varies greatly by costal/inland, rural/ urban and gender dimensions. Healthcare services have traditionally been biased towards the urban population. Using the Taiwanese experience, Hou \& $\mathrm{Li}^{18}$ propose incentive schemes for managing and reducing healthcare costs. They show a shifting population pyramid for China and recommend balanced development and significant investments in health to ease the burden of an aging population. Table 3 shows that in China the share of children in the 0-14 years age group declined from 27.7 per cent in 1990 to 16.4 per cent in 2014, while the share of adults (15-64 years) and that of the elderly (65+ years) increased from 61.5 and 4.9 per cent to 73.3 and 10.1 per cent respectively. The dependency ratio for the elderly increased from 8.3 to 13.7 per cent signifying a drastic and costly change. According to Qiu ${ }^{22}$ and Wang et al. ${ }^{23}$ China's aging population is like a 'ticking time bomb'. China has 6 million patients with dementia and, with a rapidly aging population it will have 1 million new cases every year. They predict that by 2040 China will have as many people with dementia as there will be in the rest of the world. Dong \& Ding ${ }^{12}$ look at aging 
in China both as a challenge and also as an opportunity. According to them it is crucial for the government to plan policies and allocate health and welfare resources for the future. They identify ways of addressing the needs of China's aging population and suggest that the

Table 3 Age composition and dependency ratio of population in China (1990-2014) (in 10,000)

\begin{tabular}{|c|c|c|c|c|c|c|c|c|c|c|}
\hline \multicolumn{8}{|c|}{ Age groups } & \multicolumn{3}{|c|}{ Dependency ratio } \\
\hline Year & Total & Aged 0-14 & & Aged 15-64 & & Aged 65+ & & Children & Elderly & Gross \\
\hline & Population & Population & $\%$ & Population & $\%$ & Population & $\%$ & $\% \mathbf{l}$ & $\% 2$ & $\%(1+2)$ \\
\hline 1990 & 114,333 & 31,659 & 27.7 & 76,306 & 66.7 & 6,368 & 5.6 & 41.5 & 8.3 & 49.8 \\
\hline 1995 & $|2|,|2|$ & 32,218 & 26.6 & 81,393 & 67.2 & 7,510 & 6.2 & 39.6 & 9.2 & 48.8 \\
\hline 2000 & 126,743 & 29,012 & 22.9 & 88,910 & 70.1 & 8,821 & 7 & 32.6 & 9.9 & 42.6 \\
\hline 2001 & 127,627 & 28,716 & 22.5 & 89,849 & 70.4 & 9,062 & 7.1 & 32 & 10.1 & 42 \\
\hline 2002 & 128,453 & 28,774 & 22.4 & 90,302 & 70.3 & 9,377 & 7.3 & 31.9 & 10.4 & 42.2 \\
\hline 2003 & 129,227 & 28,559 & 22.1 & 90,976 & 70.4 & 9,692 & 7.5 & 31.4 & 10.7 & 42 \\
\hline 2004 & 129,988 & 27,947 & 21.5 & 92,184 & 70.9 & 9,857 & 7.6 & 30.3 & 10.7 & 41 \\
\hline 2005 & 130,756 & 26,504 & 20.3 & 94,197 & 72 & 10,055 & 7.7 & 28.1 & 10.7 & 38.8 \\
\hline 2006 & $13 \mid, 448$ & 25,961 & 19.8 & 95,068 & 72.3 & 10,419 & 7.9 & 27.3 & 11 & 38.3 \\
\hline 2007 & 132,129 & 25,660 & 19.4 & 95,833 & 72.5 & 10,636 & 8.1 & 26.8 & 11.1 & 37.9 \\
\hline 2008 & 132,802 & 25,166 & 19 & 96,680 & 72.7 & 10,956 & 8.3 & 26 & 11.3 & 37.4 \\
\hline 2009 & 133,450 & 24,659 & 18.5 & 97,484 & 73 & 11,307 & 8.5 & 25.3 & 11.6 & 36.9 \\
\hline 2010 & $|34,09|$ & 22,259 & 16.6 & 99,938 & 74.5 & 11,894 & 8.9 & 22.3 & 11.9 & 34.2 \\
\hline 2011 & 134,735 & 22,164 & 16.5 & 100,283 & 74.4 & 12,288 & 9.1 & 22.1 & 12.3 & 34.4 \\
\hline 2012 & 135,404 & 22,287 & 16.5 & 100,403 & 74.1 & $12,7 \mid 4$ & 9.4 & 22.2 & 12.7 & 34.9 \\
\hline 2013 & 136,072 & 22,329 & 16.4 & 100,582 & 73.9 & $13,16 \mid$ & 9.7 & 22.2 & 13.1 & 35.3 \\
\hline 2014 & 136,430 & 22,560 & 16.4 & 100,470 & 73.3 & 13,760 & 10.1 & 22.5 & 13.7 & 36.2 \\
\hline $2014 / 1990$ & 1.193 & 0.713 & 0.592 & 1.317 & 1.099 & 2.608 & 1.804 & 0.542 & 1.651 & 0.727 \\
\hline
\end{tabular}

Source China statistical yearbook (2014)

\section{Urban healthy aging}

China saw the largest human migration in history after its open door policy of the 1970s. Migration has strong implications for public health services. Gong et al. ${ }^{24}$ use provincial data to provide evidence of rapid rural-to-urban migration. Growing sizes of cities and urban populations together with insufficient urban infrastructure, growing environmental problems and hazardous living conditions as well as the disease burden are major urban public health challenges. The authors suggest innovative health policies which focus on the needs of the migrants as possible solutions for meeting these challenges. They also list a number of economic, social and environmental push and pull factors driving migration in China and suggest policies to mitigate its adverse effects. Among their other suggestions are following innovative health policies that sustainably address the health needs of generations. Chao et al. ${ }^{21}$ evaluate the health status and associated factors such as community dwellings for the elderly in Nanjing in China. An elderly health assessment index system which rates different groups suggests a non-optimal general health status. The dimensions of the index include body function, self-care ability, emotional personality, and memory functions. The authors find that body functions, self-care ability and physical health declined with age faster for males as compared to females. Education, living conditions and marital status positively influenced the health status and health increased needs of the elderly can be met by improving geriatric care, education, supporting elderly institutions and elderly healthcare and changing the traditional concept of death (Table 3 ). 
urbanization. China's urban population increased by 63.2 per cent between 2000 and 2014; the corresponding increase in the share of the elderly in the urban population was 56.8 per cent. Further, the authors maintain that urbanization offers both opportunities for improvements and also leads to problems with public safety, public health and social equity. China is a major contributor to the infectious disease burden worldwide. Japan, on the other hand, provides many good examples of how to achieve urban sustainability through a better understanding of the relationship between urbanization and human health. Sixsmith et al. ${ }^{17}$ studied healthy aging at home in five European countries. They examined the relationship between home and healthy aging through

Table 4 Selected data on population in China (2000-2013) the ways in which old people perceived healthy aging by living alone at home within urban settings. Their data analysis identified five ways in which to construct elderly healthy aging with practice and policy implications: home and keeping active, managing lifestyles, health and illnesses, balancing social life and balancing material and financial circumstances. Their research suggests a number of measures for enhancing the notion of healthy aging and creating meaningful spaces. In sum, they found that the home environment played a significant role in developing and supporting personal strategies for healthy aging.

\begin{tabular}{|c|c|c|c|c|c|c|c|c|c|}
\hline \multirow[b]{2}{*}{ Year } & \multicolumn{3}{|c|}{ Population rates, $\%$} & \multicolumn{2}{|c|}{ Crude rate, $\%$} & \multicolumn{2}{|c|}{ Life Expectancy, years } & \multicolumn{2}{|c|}{ Mortality } \\
\hline & $\begin{array}{l}\text { Birth } \\
\text { (I) }\end{array}$ & $\begin{array}{l}\text { Death } \\
\text { (2) }\end{array}$ & $\begin{array}{l}\text { Natural } \\
\text { Growth (I- } \\
\text { 2) }\end{array}$ & Marriage & Divorce & $\begin{array}{l}\text { Life } \\
\text { expectancy } \\
\text { Male }\end{array}$ & $\begin{array}{l}\text { Life } \\
\text { expectancy } \\
\text { Female }\end{array}$ & $\begin{array}{l}\text { Under } \\
5 / 1000 \\
\text { birth }\end{array}$ & $\begin{array}{l}\text { Maternal// } 100,000 \\
\text { persons }\end{array}$ \\
\hline 2000 & 14 & 6.45 & 7.58 & 6.7 & 1 & 73.8 & 79.6 & 39.7 & 53 \\
\hline 2005 & 12 & 6.51 & 5.89 & 6.3 & 1.4 & 74.5 & 80.8 & 22.5 & 47.4 \\
\hline 2006 & 12 & 6.81 & 5.28 & 7.2 & 1.5 & 74.9 & 81.4 & 20.6 & 41.1 \\
\hline 2007 & 12 & 6.93 & 5.17 & 7.5 & 1.6 & 75.5 & 81.7 & 18.1 & 36.6 \\
\hline 2008 & 12 & 7.06 & 5.08 & 8.3 & 1.7 & 75.6 & 81.9 & 18.5 & 34.2 \\
\hline 2009 & 12 & 7.08 & 4.87 & 9.1 & 1.9 & 76 & 82.3 & 17.2 & 31.9 \\
\hline 2010 & 12 & 7.11 & 4.79 & 9.3 & 2 & 76.2 & 82.6 & 16.4 & 30 \\
\hline 2011 & 12 & 7.14 & 4.79 & 9.7 & 2.1 & 76 & 82.6 & 15.6 & 26.1 \\
\hline 2012 & 12 & 7.15 & 4.95 & 9.8 & 2.3 & 76.2 & 83 & 13.2 & 24.5 \\
\hline 2013 & 12.08 & 7.16 & 4.92 & 9.9 & 2.6 & .. &.. & 12 & 23.2 \\
\hline $2013 / 2000 a$ & 0.861 & 1.11 & 0.649 & 1.478 & 2.6 & 1.032 & 1.043 & 0.302 & 0.438 \\
\hline
\end{tabular}

Source China statistical yearbook (20I4); BRICS joint statistical publication (2015)

Note 'a' indicates ratio in 2013 or 2012 to 2000

Table 5 Key economic, labor market and population characteristics in China (1990-2013)

\begin{tabular}{lllllllll}
\hline & \multicolumn{2}{l}{ GDP per capita } & \multicolumn{9}{l}{ Average wage } & \multicolumn{2}{l}{ Employed at: } \\
\hline Year & $\begin{array}{l}\text { Current } \\
\text { Yuan }\end{array}$ & $\begin{array}{l}\text { Growth } \\
\text { constant } \\
\text { price }\end{array}$ & $\begin{array}{l}\text { Index, } \\
1978= \\
100\end{array}$ & $\begin{array}{l}\text { health } \\
\text { and social } \\
\text { services }\end{array}$ & $\begin{array}{l}\text { social } \\
\text { security } \\
\text { and social } \\
\text { org. }\end{array}$ & $\begin{array}{l}\text { Total in } \\
10,000\end{array}$ & $\begin{array}{l}\text { health } \\
\text { and social } \\
\text { services }\end{array}$ & $\begin{array}{l}\text { public } \\
\text { management, } \\
\text { social security } \\
\text { and org. }\end{array}$ \\
\hline 2003 & 10,542 & 109.3 & 733.1 & 16,185 & 15,355 & 73,736 & 127.8 & $1,171.00$ \\
2004 & 12,336 & 109.4 & 802.2 & 18,386 & 17,372 & 74,264 & 123.4 & $1,199.00$ \\
2005 & 14,185 & 110.7 & 887.7 & 20,808 & 20,234 & 74,647 & 122.5 & $1,240.80$ \\
2006 & 16,500 & 112 & 994.7 & 23,590 & 22,546 & 74,978 & 122.4 & $1,265.60$ \\
2007 & 20,169 & 113.6 & $1,129.60$ & 27,892 & 27,731 & 75,321 & 125 & $1,291.20$ \\
2008 & 23,708 & 109.1 & $1,232.10$ & 32,185 & 32,296 & 75,564 & 126 & $1,335.00$ \\
2009 & 25,608 & 108.7 & $1,339.00$ & 35,662 & 35,326 & 75,828 & 129.5 & $1,394.30$ \\
2010 & 30,015 & 109.9 & $1,471.70$ & 40,232 & 38,242 & 76,105 & 131.4 & $1,428.50$ \\
2011 & 35,198 & 108.8 & $1,600.90$ & 46,206 & 42,062 & 76,420 & 135 & $1,467.60$ \\
2012 & 38,459 & 107.1 & $1,715.10$ & 52,564 & 46,074 & 76,704 & 137.7 & $1,541.50$ \\
2013 & 41,908 & 107.1 & $1,837.50$ & 57,979 & 49,259 & 76,977 & 147 & $1,567.00$ \\
$2013 / 2003$ & 3.975 & 0.98 & 2.506 & 3.582 & 3.208 & 1.044 & 1.15 & 1.338 \\
\hline
\end{tabular}

Source China statistical yearbook (2014) 
Black et al. ${ }^{19}$ explored the role of urban design in cycling behaviors and healthy aging. They suggest that a good urban design provides an inclusive environment for elderly cyclists. A better understanding of elderly cyclists' experiences and their perceptions about the urban environment influence their mobility and physical activities. Some European metropolitans combine initiatives in urban design, policy and inclusive infrastructure for facing aging and health challenges. Black et al. ${ }^{19}$ research provides an understanding of the quality of urban design and features of the built environment that affect participation in cycling with the aim of contributing towards a healthy aging agenda.

\section{Investments in well-being}

This section provides a review of literature on investments in healthy aging that can have positive effects on healthy aging outcomes by reducing social inequalities and meeting the needs and costs of elderly care. Table 5 shows positive trends of investing in health and social services, social security and social organizations on GDP per capita, wages and employment. The type of investment is related to changed attitudes towards a multidimensional view of well-being; an assessment of the effects of therapy on the quality of life; investments in child heath to foster healthy aging; promoting dietary patterns and exercise habits with health linkages; the use of an integrative approach to learning; community-based care; and an emphasis on the determinants of successful aging.

\section{Investments in the well-being of specific groups}

The Chinese central and provincial governments have made significant investments in healthcare infrastructure. Improved knowledge and technological developments have influenced birth and death rates and also the growth rates of the natural population. GDP per capita grew 18.4 times between 1978 and 2013. This rapid growth enabled investments in health, social services and social organizations (Table 5)(Table 6). It also led to increased disposable incomes leading to high consumption of utilities, housing, education, transportation, communication, health, pension and other welfare enhancing activities (Table 6). However, it also led to negative environmental externalities.

Here Unlike the Marmot Review's (2010) argument that societies should focus on reducing health inequalities by removing unfair socioeconomic gradients in health and reducing social inequalities, ${ }^{27}$ argue that a better goal would be improving health, income and socioeconomic outcomes for the most disadvantaged through direct health interventions particularly in early childhood. In contrast to economists with a simple focus on income or consumption per capita as a measure of well-being, researchers also suggest a multidimensional view of well-being as being more plausible. ${ }^{28,29}$ Dimensions of wellbeing should ideally include consumption, wealth, health, education, housing, personal activity, political voice and governance, social connectedness, environmental conditions and personal and economic securities. These are also in line with Deaton' $\mathrm{s}^{30}$ analysis of data on life and health satisfaction looking at their relationship with income, age and life expectancies. He found average life satisfaction to be strongly related to per capita income.

$\mathrm{Kim}^{31}$ studied the effects of art therapy on healthy aging in older Korean American adults for promoting well-being and a better quality of life. The objective of Kim's study was to quantitatively assess the effects of art therapy using effect, anxiety and self-esteem as instruments for outcomes. The results show positive effects of therapy which promoted better health for older individuals in terms of reducing negative emotions, improving self-esteem and decreasing anxiety. It is important to address the full aging process including the younger population in aging research. Felix et al. ${ }^{32}$ have developed a conceptual framework for child health which they treat as a dynamic state permitting optimal physical, mental and social functioning. They used an optimal child quality of life as the starting point for healthy aging research. They propose five core dimensions of child health. This conceptualization of child health and its dimensions can serve as a platform for building a framework with a broader focus on healthy aging across the life course.

Table 6 Development of selected income, resources and investment measures in China (1990-20|3)

\begin{tabular}{|c|c|c|c|c|c|c|c|c|c|c|c|c|c|}
\hline & Per capita: & & & & & & $\begin{array}{l}\text { Investment } \\
\text { in: }\end{array}$ & & Transportation: & & Internet & Welfare & \\
\hline Year & $\begin{array}{l}\text { Disposable } \\
\text { income, } \\
\text { urban, } \\
\text { RMB }\end{array}$ & $\begin{array}{l}\text { Disposable } \\
\text { income, } \\
\text { rural, } \\
\text { RMB }\end{array}$ & $\begin{array}{l}\text { Water } \\
\text { use in } \\
\text { CuM }\end{array}$ & $\begin{array}{l}\text { Energy } \\
\text { consumption, } \\
\text { kg of SCE }\end{array}$ & $\begin{array}{l}\text { Floor } \\
\text { space, } \\
\text { urban, } \\
\mathrm{m} 2\end{array}$ & $\begin{array}{l}\text { Floor } \\
\text { space, } \\
\text { rural, } \\
\text { m2 }\end{array}$ & $\begin{array}{l}\text { Treatment } \\
\text { of } \\
\text { industrial } \\
\text { pollution, } \\
\text { in } 10,000 \\
\text { yuan }\end{array}$ & $\begin{array}{l}\text { Fixed } \\
\text { assets, } \\
\text { in } 100 \\
\text { million } \\
\text { yuan }\end{array}$ & $\begin{array}{l}\text { Passenger km, } \\
\text { total }\end{array}$ & $\begin{array}{l}\text { Civil } \\
\text { vehicles, } \\
\text { in } \\
10,000\end{array}$ & $\begin{array}{l}\text { Number } \\
\text { of } \\
\text { users, in } \\
10,000\end{array}$ & $\begin{array}{l}\text { Basic } \\
\text { pension, } \\
\text { in } \\
10,000 \\
\text { persons }\end{array}$ & $\begin{array}{l}\text { Health } \\
\text { personnel }\end{array}$ \\
\hline 2000 & 6,280 & 2,253 & 435 & 123.7 & .. & 24.8 & $2,347,895$ & 32,918 & $|2,26|$ & 1,609 & 2,250 & 13,617 & 159,212 \\
\hline 2001 & 6,860 & 2,366 & 438 & 127.2 & .. & 25.7 & $1,745,280$ & 37,214 & 13,155 & 1,802 & 3,370 & 14,182 & 165,855 \\
\hline 2002 & 7,703 & 2,476 & 429 & 134 & 24.5 & 26.5 & I,883,663 & 43,500 & 14,126 & 2,053 & 5,910 & 14,737 & 175,444 \\
\hline 2003 & 8,772 & 2,622 & 413 & 153.4 & 25.3 & 27.2 & $2,2|8,28|$ & 55,567 & $|3,8| \mid$ & 2,383 & 7,950 & 15,507 & 183,103 \\
\hline 2004 & 9,422 & 2,936 & 428 & 175.7 & 26.4 & 27.9 & $3,081,060$ & 70,477 & 16,309 & 2,694 & 9,400 & 16,353 & $|92,61|$ \\
\hline 2005 & 10,493 & 3,255 & 432 & 194.1 & 27.8 & 29.7 & $4,581,909$ & 88,774 & 17,467 & 3,160 & 11,100 & 17,488 & 199,734 \\
\hline 2006 & 11,759 & 3,587 & 442 & 211.8 & 28.5 & 30.7 & $4,839,485$ & 109,998 & 19,197 & 3,697 & 13,700 & 18,766 & 206,958 \\
\hline 2007 & 13,786 & 4,140 & 441 & 233.8 & 30.1 & 31.6 & $5,523,909$ & 137,324 & 21,593 & 4,358 & 21,000 & 20,137 & 214,748 \\
\hline 2008 & $|5,78|$ & 4,761 & 446 & 240.8 & 30.6 & 32.4 & $5,426,404$ & 172,828 & 23,197 & 5,100 & 29,800 & 21,891 & 223,623 \\
\hline 2009 & 17,175 & 5,153 & 448 & 258.3 & 31.3 & 33.6 & $4,426,207$ & 224,599 & 24,835 & 6,281 & 38,400 & 23,550 & 233,553 \\
\hline 2010 & 19,109 & 5,919 & 450 & 278.3 & 31.6 & 34.1 & $3,969,768$ & 251,684 & 27,894 & 7,802 & 45,730 & 35,984 & 241,156 \\
\hline 2011 & 21,810 & 6,977 & 454 & 278.3 & 32.7 & 36.2 & $4,443,610$ & 311,485 & 30,984 & 9,356 & 51,310 & 61,573 & 250,258 \\
\hline 2012 & 24,565 & 7,917 & 455 & 293.8 & 32.9 & 37.1 & $5,004,573$ & 374,695 & 33,383 & 10,933 & 56,400 & 78,796 & 258,283 \\
\hline 2013 & 26,955 & 8,896 & 456 &.. &.. &. & $8,676,647$ & 446,294 & 27,572 & 12,670 & 61,758 & 81,968 &.. \\
\hline $2013 / 2000 a$ & 4.292 & 3.949 & 1.048 & 2.375 & 1.343 & 1.496 & 3.696 & 13.558 & 2.249 & 7.874 & 27.448 & 6.02 & 1.622 \\
\hline
\end{tabular}

Source China statistical yearbook (2014)

Note 'a' indicates alternative ratio of the most recent period to the earliest period available 


\section{Healthy aging and diet}

Research shows that diet and health are strongly linked. Diet is an efficient way of allowing for healthy aging. Heinrich et al. ${ }^{16}$ assess how diet evolved in the past century to make inferences about diet in the future. Of particular interest are their explanations of changes in dietary habits and their impact on health. Besides being healthy the food must also be convenient and easy to prepare. Thus, healthy aging requires looking at various aspects of food. According to Sadler $^{33}$ trends at the interface of health and diet are defined by six keywords: glycemic index, healthy heart, well-being, daily dosing, low fat to right fat and functional food. A number of dietary patterns are associated with reduced risks for cardiovascular and age-related diseases. Traditional Okinawa, Mediterranean, the DASH (Dietary Approach to Stop Hypertension) and the Portfolio (cholesterol lowering) diets share some characteristics which have gained significant attention from researchers and health and social policy planners. The important shared features of these healthy dietary patterns include high intake of unrefined carbohydrates, moderate protein intake with emphasis on vegetables/legumes, fish and lean meats as sources, a healthy fat profile and daily Jasmine tea and physical activity (Table 7). ${ }^{34}$

Together they reduce the socioeconomic costs of chronic diseases and promote healthy aging, longevity and quality of life. Effective diet related public health policies and programs can do much to mitigate risks and help individuals remain healthy as they age. Along similar lines, Zhao et al. ${ }^{35}$ investigate empirical relationships between diet, chronic health outcomes and health information. They disentangled the role of information on the health status of consumers by adjusting their lifestyles. On receiving negative health information individuals were expected to adjust their diets in a healthier direction. The authors present evidence of the effects of hypertension on food consumption based on Chinese data. Their results show that changes in food consumption and health outcomes were influenced by individuals' levels of education and income. Healthy dietary and exercise habits contribute to healthy aging and increasing life expectancies. Hammar et al. ${ }^{36}$ refer to certain types of diets that can prevent or reduce obesity and the risk of diseases. Exercise and activities suited for individuals can also be tailored to reduce the risk of cardiovascular diseases. Thus, age-adjusted modifiable lifestyle factors such as diet and exercise can be strong promoters of healthy aging, improved well-being and preventing diseases as they play a role in maintaining optimal cognitive, mental and physical health in the advanced age.

\section{Other factors supporting healthy aging}

Increased life expectancies and the need for maintaining the health of the elderly are key challenges facing governments across the world. Shneerson et al..$^{37}$ find that health systems based on a biomedical model with focus on core specific conditions are ill-suited for the complex needs of the elderly. The authors suggest interpersonal education aimed at training multi-disciplinary healthcare students and members of communities as being more beneficial in dealing with some of these challenges. A shared care and integrative approach to learning can be achieved by getting patients and the public to collaborate in supporting healthy aging and improving links to social care. It is expected that the new approach will promote a community-based, preventive, integrative, interactive and positive approach to healthy aging. Silva $\&$ Correia ${ }^{38}$ discuss ways in which the web and telecommunications have brought beneficial changes to people's daily lives. However, advancements in the digital world have also created a digital divide
Table 7 Ten characteristics of the traditional Okinawa diet

\begin{tabular}{|c|c|}
\hline Items & The characteristics \\
\hline I & Low caloric intake \\
\hline 2 & $\begin{array}{l}\text { High consumption of vegetables (particularly root and green- } \\
\text { yellow vegetables) }\end{array}$ \\
\hline 3 & High consumption of legumes (mostly soybean in origin) \\
\hline 4 & $\begin{array}{l}\text { Moderate consumption of fish products (more in coastal } \\
\text { areas) }\end{array}$ \\
\hline 5 & Low consumption of meat products (mostly lean pork) \\
\hline 6 & Low consumption of dairy products \\
\hline 7 & $\begin{array}{l}\text { Low fat intake (high mono and polyunsaturated-to-saturated } \\
\text { fat ratio; low omega) }\end{array}$ \\
\hline 8 & Emphasis on low-Gl carbohydrates \\
\hline 9 & High fiber intake \\
\hline 10 & Moderate alcohol consumption \\
\hline
\end{tabular}

Source Adapted from Willcox et al. ${ }^{34}$

from the perspective of internet access and use. Elderly people, in particular, have been affected by this divide as they lack relevant skills. New solutions tailored to the needs of the elderly therefore need to be suggested. Active Brain is a social online cognitive training platform. It covers brain training, stress sharing and elderly support to maintain elders' interpersonal communications by being socially connected with others. In order to understand how technology and social networking can enhance elders' lives and promote active aging, Silva \& Correia ${ }^{38}$ discuss the challenges of changing paradigms and adjusting to new trends in emerging technologies. There is a desire to identify factors associated with successful aging in terms of health related to the quality of life. Dahany et al. ${ }^{20}$ identified such factors to investigate the association between successful aging and sociodemographic, psychological, physical and behavioral factors. Their results show that lower weight, regular physical activity and religious beliefs positively influenced aging, while psychological distress, co-morbidities and obesity influenced it negatively. Similar results related to psychological, physical and regular physical activity and a balanced diet are found in other studies which serve as elements of policies and programs for promoting healthy aging.

\section{An Optimal healthy aging policy in china}

Available statistics on the present demographic structure and forecasts for the population structure of the elder cohort in China suggest serious economic and social challenges. These challenges can be best met by optimal healthy aging. Some of the main reasons for the increasing number of elderly people in the country are the one-child policy of the 1970s, technological progress, increased education levels, health insurance and improved living standards. These have jointly led to improved health and subsequent continuous increasing average life expectancies. However, they have also contributed to deteriorating trends in personal behavior and health like growing obesity, smoking and drinking habits. Other significant changes include pollution, the changed one-child policy, increased fertility, continued rural-to-urban migration, an increased overall dependency ratio and dependency on public health services and care provisions. In the long term these will negatively influence China's labor productivity, economic growth and competitiveness. The recent decades of high economic growth 
in China have generated resources for investments in education, knowledge and technological advancements. These have further strengthened their causal relationships. The state has made significant investments in productive and well-being infrastructure. As a result, changes are observed in birth and death rates and the living conditions of the population. Increases in production and consumption, in particular in transport, water and energy resources have negatively influenced the environment. Table 6 shows that investments in fixed assets, housing, provisions of basic pension, health insurance and health services, social security and organizations have increased. These have positively influenced longevity and healthy aging. They are important means for coping with the challenges of aging. ${ }^{39}$ Since the health of the older population is a key determinant of its need for resources and care, it is important to consider aging as an opportunity to search for optimal healthy aging to meet the economic and social challenges of an aging population. Investments in healthy aging contribute to general economic and social well-being and reduce the pressure on providing services to a rapidly growing aging population. A number of alternative approaches can be used to meet the rapidly growing aging population in China. These include strategies, policy practices, organizational changes, resources allocation and other measures employed for promoting healthy aging.

\section{The current state and conditions}

A persistent increase in average life expectancy regardless of the level of development and location will bring social, economic, political and biomedical challenges both for current and future generations. Approaches in existing research aim at developing interventions to enhance the quality of life while increasing its length and on developing cost efficient methods given the limited resources allocated to various competing priorities of different age cohorts. A segment of literature which emphasizes on health inequalities and healthy aging in the context of a fair society has received significant attention. This has led to a number of inquiries into the state of health inequalities and fairness. The Marmot Review can serve as a model to shed light on health inequalities in China and to make policymaking more health inequality reducing. Health inequality refers to differences in healthiness across the population. The degree can be reduced by public health care provision. Gains can also be made by leaping shorter distances between accumulated knowledge and economically implementable policies. Literature employs different approaches for measuring healthy aging including a multidimensional measure with focus on biological aging, the protection of longevity and genetic healthy aging. Biological aging as a complex process can be measured by tools developed by identifying the key features of healthy aging. Prediction of healthy aging by using N-gylcan profiles has been suggested as a suitable tool for monitoring the healthiness of aging and for assessing the effectiveness of aging interventions. Another approach focuses on identifying genes related to healthy aging and longevity. These and other approaches can be used in research on China. Various community programs are being developed to actively improve social and healthcare systems in societies facing the challenges of aging. These societies promote health and wellbeing and prevent or minimize the prevalence of various diseases. The aim of the active aging policy implementable in the Chinese case is extending healthy life expectancies and the quality of life as people age while maintaining autonomy for the older people. For instance, action plans against falls which is the most common and frequent home accident are common preventive actions. Another area of prevention is finding long-lasting and cost effective interventions for chronic brain disorders such as Alzheimer's disease.

The share of the elderly in China's total population is increasing fast. The distinct features of Chinese society are the elderly depending on their families for care, a decline in the number of children and rapid rural-to-urban migration leaving the elderly behind. As a result, the current level and quality of services falls short of the needs of the elderly. Improving education, supporting elderly care institutions and making changes in traditional care for the elderly are recommended. In general, the health of the elderly remains a key determinant in their care needs. The unfairness and disparities in the health insurance system and insufficient resources available for elderly care are factors that lead to sub-optimum services. Developing communitybased primary healthcare and active policy interventions will provide improved solutions.

\section{Policy recommendations based on existing best practices}

The focus of growing economic literature on healthy aging is on the cost of healthcare for an aging population; some others have investigated the benefits of investments in healthy aging and health status and the factors influencing them. Existing conditions imply that there is a need to plan seriously so as to be able to cope with increasing demands of elderly care. Hence, planning healthcare and providing incentive schemes to manage and reduce healthcare costs for various groups will help in finding balanced development and investment in health to ease the burden of the aging population. An increasing number of patients with dementia implies that policy planning and measures and allocation of resources for the future should be given priority. Improved geriatrics, education, supporting elderly institutions and changing care traditions are among the other measures which need to be adopted to meet the needs of the elderly in China more efficiently. Rural-to-urban migration in China can have strong implications for public safety, public health, healthcare services and social equity. Growing city sizes and urban populations combined with insufficient infrastructure, growing environmental problems, hazardous living conditions and disease burden are new public health challenges.

In this regard innovative health policies can help meet the growing demand for research resources to close the knowledge gap to sustainably address the health needs of generations. A multidimensional index rating the general health status of the elderly by assessing dimensions for different groups will be useful. This index can help assess the influence of the physical and social environment, individual characteristics and family support on elders' well-being. The relationship between home and healthy aging within urban settings shows a number of efficient ways of dealing with healthy aging. These can be adapted to allow the home environment to play a significant role in developing and supporting personal strategies for healthy aging and for managing elderly healthcare in China. A combination of urban design, policy and infrastructure initiatives should influence mobility and physical activities by the elderly. Such policies are implementable in China. Various reviews argue that societies should focus on reducing health inequalities and improving health, income and socioeconomic outcomes for the most disadvantaged in society through direct health interventions; these too are implementable in China. A multidimensional view of well-being focusing on diverse aspects is also desired. Child health as a starting point for research in healthy aging will play a strong role in this. 
Research also shows that the link between health, diet and physical activity is vital. An adjusted and modifiable diet tailormade for specific groups and activities to allow for healthy aging is important. The health-diet linkage should also be accounted for when discussing changes in habits and deriving factors for health trends. Diets are associated with reduced obesity leading to reduced risks of cardiovascular and age-related costly diseases. In this regard elements of the Okinawa, Mediterranean, DASH and Portfolio diets should be promoted to maintain optimal cognitive, mental and physical health in an advanced age. Investments in education and household incomes can influence optimal changes in food consumption leading to positive health outcomes. Other factors which support healthy aging include an integrative approach involving patients and the public and establishing links to social care. The resulting system should promote community-based, preventive, integrative and a positive approach to healthy aging. The web, telecommunications and social online cognitive platforms for maintaining interpersonal communications and social connectedness among the elderly are attractive measures in an information society. These measures complement other identified socio-demographic, psychological, physical and behavioral factors with a positive association with successful aging and a better quality of life.

\section{Summary and Conclusion}

This study provided a review of literature on healthy aging focusing on alternative approaches, policies and practices to ease pressures of an aging population. The objective was not to create a new synthesis rather to shed lights on the combined measures easing the 'ticking time bomb' pressure of ageing population in China. The review also proposed a blend of policies to form an optimal perspective on healthy aging in China. The major reasons for the elderly population increasing in China are the one-child policy, higher education, technological progress, health insurance and improved material standards. These explain continuously increasing life expectancies along with deteriorating trends in personal behavior such as smoking, obesity and pollution which are contributing to an increased need for costly healthcare. None of the former categories should be reversed, while the behavioral factors can be influenced through preventive investment measures to reduce resource needs in the long run. These will also improve the general economic and social well-being in society. A summary of the present situation in China reveals that health in general should refer to physical, mental and social well-being, while healthy aging should be defined in a multidimensional manner as developing and maintaining health and functions in the elderly. The proposed measures focus, among others, on biological aging, protection of longevity, generic health aging and identifying genes related to healthy aging and longevity. In recent decades, awareness about the aging problem and developing strategies, policies, organizations, resources and practices to cope with aging pressures have been noticed. There is also evidence of the long term social and economic benefits of such investments. The current interdisciplinary research's focus is on developing therapeutic interventions with high resource-use priorities to enhance the quality of life and for developing cost effective care methods. Among the active measures being taken are coping with health inequalities and fairness; reducing the distance between knowledge and policies; developing various integrative community programs; investing in education and public safety; disease prevention; improved geriatrics; changes in care traditions; extending healthy lives and their quality; and cost effective interventions for chronic brain disorders. The relationship between home and healthy aging, interpersonal and social connectedness, health-diet linkages, maintaining optimal cognitive and mental, physical and social relationships in an age of urbanization and in an information society are crucial when it comes to healthy aging. ${ }^{40}$

\section{Acknowledgement}

None.

\section{Conflict of intrest}

None.

\section{References}

1. Rasmussen LJ, Sander M. Ageing, Longevity and Health. Mechanisms of Ageing and Development. 2011;132:522-532.

2. Marmot M, Bell R. Fair society, healthy lives. Public Health. 2012;126(Suppl 1):S4-S10.

3. Marmot M, Allen J, Goldblatt P. A social movement, based on evidence, to reduce inequalities in health. Soc Sci Med. 2010:71(7):1254-1258.

4. Michael Marmot, Peter Goldblatt, Jessica Allen, et al. Fair society, healthy lives (The Marmot Review). The Institute of Health Equity: London;2010.

5. Subramanyan MA, Kawachi I, Subramanian SV. Reactions to Fair Society, Healthy Lives (The Marmot Review). Soc Sci Med. 2010;71(7):12211222

6. Chandra A, TS Vogl. Rising up with shoe leather? A comment on Fair Society, Healthy Lives (The Marmot Review). Soc Sci Med. 2010;71(7):1227-1230.

7. Lara JA, Godfrey A, et al. Towards Measurement of the Healthy Ageing Phenotype in Lifestyle-Based Intervention Studies. Maturitas. 2013;76(2):189-199.

8. Vanhooren V, Liu X, Evans E, et al. N-glycan profiles as tools in diagnosis of hepatocellular carcinoma and prediction of healthy human ageing. Mechanisms of Ageing and Development. 2009;130(1-2):92-97.

9. Shytthe A, Valensin S, Jeune B et al. Design, recruitment, logistics, and data management of the GEHA (Genetics of Healthy Ageing) project. Exp Gerontol. 2011;46(11):934-945.

10. Agren G, Berensson k. Healthy Ageing: A Challenge for Europe. The Swedish National Institute of Public Health. 2006;29:1-258.

11. Zhao Y, Smith JP, Strauss J. Can China aged healthily? Comment. The Lancet. 2014;384(9945):723-724.

12. Dong B, Ding Q. Ageing China: A Challenge or an Opportunity. Special Articles. Journal of the American Medical Directors Association. 2009;10(7):456-458.

13. Smith JP, Strauss J, Zhao Y. "Healthy Ageing in China". J Econ Ageing. 2014;4:37-43.

14. Bloom DE, Eggleston KN. The economic implications of population ageing in China and India: Introduction to the special issue. The Journal of the Economics of Ageing. 2014;26(4):1-154.

15. Wang XQ, Chen PJ. Correspondence, Population ageing challenges health care in China. The Lancet. 2014;383:1-870.

16. Heinrich M, Prieto JM. Diet and Healthy Ageing 2100: Will We Globalise Local Knowledge System? Ageing Res Rev. 2008;7(3):249-274.

17. Sixsmith J, Sixsmith A, Malmgren Fange A, et al. Healthy ageing and home: The perspectives of very old people in five European countries. Soc Sci Med. 2014;106:1-9. 
18. Hou JW, Li K. The Ageing of the Chinese Population and the Cost of Health Care. The Social Science Journal. 48(3):514-526.

19. Black P, Street E. The Power of Perceptions: Explaining the Role of Urban Design in Cycling Behaviours and Health Ageing. Transportation Research Procedia. 2014;4:68-79.

20. Dahany MM, Drame M. Factors Associated with Successful Ageing in Persons Aged 65 to 75 Years. European Geriatric Medicine. 2014;5(6):365-370.

21. Chao J, Li y, Xu H, et al. Health Status and Associated Factors among the Community-Dwelling Elderly in China. Arch Gerontol Geriatr. 2013;56(1):199-204.

22. Qiu J. In Context, Ticking time bomb faced by China's ageing population. The Lancet. 2017;6(7):582-583.

23. Wang XQ, Chen PJ. Correspondence, Population ageing challenges health care in China. The Lancet. 2014;383:1-870.

24. Gong P, Liang S, Carlton EJ, et al. Urbanisation and health in China. The Lancet. 2012;379(9818):843-852.

25. Cheng Y, Rosenberg MW. Aging, health and place in residential care facilities in Beijing, China. Soc Sci Med. 2011;72(3):365-372.

26. Li XH, Liu JL, Valerie Gibson, et al. Urban sustainability and human health in China, East Asia and Southeast Asia. Current Opinion in Environmental Sustainability. 2012;4(4):436-442.

27. Canning D, Bowser D. Investing in health to improve the well-being of the disadvantaged: Reversing the argument of Fair Society, Healthy Lives (The Marmot Review). Soc Sci Med. 2010;71(7):1223-1226.

28. Bersisa M, Heshmati A. Multidimensional measure of poverty in Ethiopia: Factor and stochastic dominance analysis. Springer. 2016:1-281.

29. Maasoumi E, Hu T. Weights and substitution degree in multidimensional well-being in China. Journal of Economic Studies. 2015;42(1):4-19.

30. Deaton A. Income, Health, and Well-being around the World: Evidence from the Gallup World Poll. Journal of Economic Perspectives. 2008;22(2):53-72.
31. Kim SK. A randomized, controlled study of the effects of art therapy on older Korean-Americans' healthy aging. The Arts in Psychotherapy. 2013;40(1):158-164.

32. Felix JF, Voortman T, Sajjad A, et al. Health in children: A conceptual framework for use in healthy ageing research. Maturitas. 2014;77(1):4751.

33. Sadler J. Future Health Trends in Food and Drinks: growth opportunities in daily dosing, GI, heart health, right fats and food. UK; 2005.

34. Willcox DC, Scapagnini G, Willcox BJ. Healthy aging diets other than the Mediterranean: A focus on the Okinawan die'. Mech Ageing Dev. 2014; $136: 148-162$

35. Zhao M, Konishi Y, Glewwe P. Does information on health status lead to a healthier lifestyle? Evidence from China on the effect of hypertension diagnosis on food consumption. Journal of Health Economics. 2013;32(2):367-385.

36. Hammar M, Ostgren CJ. Healthy aging and age-adjusted nutrition and physical fitness. Best Pract Res Clin Obstet Gynaecol. 2013;27(5):741752.

37. Shneerson C, Bartlett D, Janet Lord, et al. supporting healthy ageing: Training multi-disciplinary healthcare students. European Journal of Integrative Medicine. 2014;6(1):104-111.

38. Silva M. Correia S. Active Brain: Online Social Platform for Active and Healthy Ageing. Procedia Computer Science. 2014;27:38-45.

39. Erten Lyons D, Sherbakov LO, Piccinin AM, et al. Healthy Ageing and Preclinical Dementia: The United States-Israel Longitudinal Database Project. Alzheimer's and Dementia. 2010;6(6):475-481.

40. CSDH. Closing the gap in a generation: health equity through action on the social determinants of health. World Health Organization: Geneva; 2008. 